\title{
Erratum to: Safety and tolerability of Bifidobacterium longum subspecies infantis EVC001 supplementation in healthy term breastfed infants: a phase I clinical trial
}

Jennifer T. Smilowitz ${ }^{1,2 *}$, Jackelyn Moya ${ }^{1}$, Melissa A. Breck' ${ }^{1}$ Chelsea Cook ${ }^{1}$, Annette Fineberg ${ }^{3}$, Kathleen Angkustsiri ${ }^{4}$ and Mark A. Underwood ${ }^{5}$

\section{Erratum}

Following the publication of this article [1], it was brought to our attention that the lower SD bars in Fig. 3a were unfortunately omitted. Furthermore, the bar graphs were erroneously referred to as "dot plots" in the figure legend. The correct Fig. 3a is presented below:

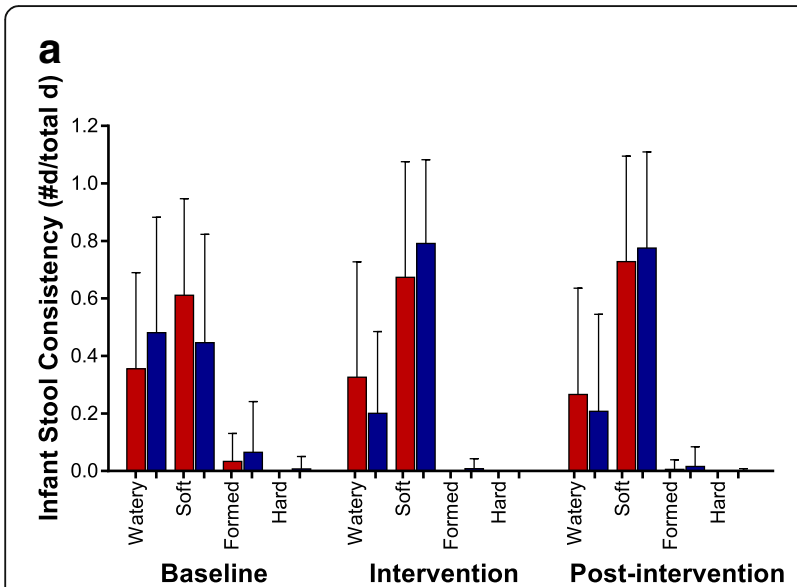

Fig. 3 Infant stool consistency. a Mean + SD of the proportion in reported infant stool consistency for the LS (red bar) and BiLS (blue bar) groups during the Baseline, Intervention, and Post-intervention periods. $n=34$ for each group during the Baseline and Intervention periods, $n=33$ for the LS group, and $n=34$ for the BiLS group during the Post-intervention period
The above have been updated in the original version of the article.

\section{Author details}

'Department of Food Science and Technology, University of California, Davis, CA, USA. ${ }^{2}$ Foods for Health Institute, University of California, One Shields Ave, Davis, CA 95616, USA. ${ }^{3}$ Sutter Health, Sutter Davis Hospital, Davis, CA, USA.

${ }^{4}$ UC Davis MIND Institute, University of California, Davis, CA, USA.

${ }^{5}$ Department of Pediatrics, UC Davis Children's Hospital, Sacramento, CA, USA.

Received: 3 August 2017 Accepted: 3 August 2017

Published online: 15 August 2017

\section{Reference}

1. Smilowitz J, et al. Safety and tolerability of Bifidobacterium longum subspecies infantis EVCO01 supplementation in healthy term breastfed infants: a phase I clinical trial. BMC Pediatr. 2017;17:133. doi:10.1186/s12887-017-0886-9.

* Correspondence: jensm@ucdavis.edu

'Department of Food Science and Technology, University of California, Davis, CA, USA

${ }^{2}$ Foods for Health Institute, University of California, One Shields Ave, Davis,

CA 95616, USA

Full list of author information is available at the end of the article 